\title{
Transformative learning opportunities during interprofessional healthcare practice experiences in higher education: Viewed through the lens of a threshold concepts framework
}

\author{
C. J. Morgan, A. Bowmar, S. McNaughton \& B. Flood
}

\begin{abstract}
Introduction: The transformative nature of collaborative interprofessional learning experiences, for both students and educators, signals the importance of identifying transitional learning that transcends professional or disciplinary boundaries for patientcentred care. Threshold concepts (Meyer \& Land, 2003) provide a conceptual framework for viewing the way students grapple with new ways of knowing and practising, both individually and collectively, and have been used to inform understanding of how students progress their knowledge, skills and dispositional attributes through the process of collaborative interprofessional practice. This paper identifies and provides insight into transformative learning following students' and educators' engagement in a practice-based program.
\end{abstract}

Methods: This paper reports the qualitative interpretive findings from a mixed methods study on the learning experiences of 14 health students from eight undergraduate health programs and five clinical educators, two interprofessional facilitators and two health administrators engaged in collaborative interprofessional practice in a university context.

Results: Interpretive thematic analysis of student and educator focus-group transcripts revealed that transformative learning occurred through cumulative, collaborative learning experiences. The transformative learning thresholds identified in this study included: broadening perspectives on healthcare practice; strengthening sense of

School of Interprofessional Health Studies, AUT University, Auckland, New Zealand

Correspondence

C. Jane Morgan

School of Interprofessional Studies

Faculty of Health and Environmental Sciences

Auckland University of Technology

Private Bag 92006

90 Akoranga Drive, Northcote

Auckland 0627

New Zealand

Tel: +649219999 ext. 7023

Email: jmorgan@aut.ac.nz 
professional self; gaining an appreciation of holistic patient care; and actioning holistic, patient-centred healthcare.

Conclusions: The threshold concepts framework provided a lens for viewing the experiential learning processes that occurred during the student-led interprofessional program and the transformative nature of knowledge and skills acquisition and integration during interprofessional learning opportunities. The identification of four transformative threshold concepts relevant to interprofessional learning for collaborative practice will assist educators to better understand how to support and challenge learners in collaborative-practice encounters.

Keywords: interprofessional practice; students; educators; transformative learning; threshold concepts; collaboration; patient-centred health care.

\section{Introduction}

Interprofessional practice has been endorsed by the World Health Organization (WHO) in their advocacy of collaborative practice in healthcare, which they define as "when multiple health workers from different professional backgrounds provide comprehensive services by working [together] with patients, their families, carers and communities to deliver the highest quality of care across settings" (WHO, 2010, p. 13). WHO also identify effective teamwork among health professions as occurring when members of a team understand and optimise the different roles, knowledge and skills within the team. Thus, effective collaborative teams, comprised of members from a number of health professions, draw on and are informed by knowledge, skills and roles from all members to optimise health outcomes (Weller, Thwaites, Bhoopatker, \& Hazell, 2010).

Experiencing interprofessional practice through the "doing" of practice in authentic contexts is known to be beneficial in supporting students' learning of how to collaborate effectively with other health professions (Black et al., 2013; Fallow, Goodwin \& Sevilla, 2015; Grant, MacKenzie, \& Clemson, 2015; Lie, Forest, Walsh, Banzali, \& Lohenry, 2016). The imperative for developing this capability is clearly evidenced in reports on the future health workforce (WHO, 2010, 2013, 2016), in seminal work by Frenk et al. (2010) and in literature from educators spanning the education-practice spectrum (Barr, Gray, Helme, Low, \& Reeves, 2016; Morgan, 2017; Neve, 2019; Thistlethwaite, 2012).

Interprofessional education is proposed as a constructivist pedagogy "for the explicit purpose of improving interprofessional collaboration or the health/wellbeing of patients/clients, or both" (Reeves, Perrier, Goldman, Freeth, \& Zwarenstein, 2013, p. 2). Although educators have explored ways to provide engaging interprofessional learning experiences for improving students' collaborative communication and teamwork skills, there has been limited curriculum change in higher education to overtly position interprofessional practice within health profession education (Olson \& Bialocerkowski, 2014). This is despite the growing call for students from distinct professions to learn and practise together, with the aim of developing knowledge and skills for working in 
collaborative teams (Berger et al., 2017; Cox, Cuff, Brandt, Reeves, \& Zierler, 2016; Farlow, Goodwin, \& Sevilla, 2015; Reeves, 2016; Reeves et al., 2013).

\section{A conceptual framework for viewing interprofessional practice}

While interprofessional learning opportunities are becoming increasingly widespread in preparing existing and future practitioners for collaborative teamwork (Reeves et al., 2013), there have been calls to consider, develop and apply theoretical frameworks to interprofessional education programs (Barr, 2013; Craddock, O’Halloran, McPherson, Hean, \& Hammick, 2013; Hean et al., 2013; Hean, Anderson, Green, Pitt, \& O'Halloran, 2016; Reeves, 2016; Reeves \& Hean, 2013) and to inform, structure and sustain interprofessional practice in action (Barr, 2013; Green, 2013; Hean et al., 2013; Reeves, Boet, Zierler, \& Kitto, 2015; Watkins, 2016). Threshold concepts (Meyer \& Land, 2003) provide a conceptual framework for explicitly viewing the way students grapple with new ways of knowing and practising, both individually and collectively. Meyer and Land (2006) identify threshold concepts as transformative and integrative concepts that lead to "a transformed way of understanding, or interpreting, or viewing something without which the learner cannot progress" (p. 4). Furthermore, threshold concepts act as portals or "linkages", shifting students into altered or even completely new ways of thinking about a particular knowledge or practice field (Meyer \& Land, 2006). These portals are "conceptual gateways to ... integrate previously unrelated aspects of [knowledge and practice] by enabling new ways of thinking about it" (Zepke, 2013, p. 99).

Threshold concepts have been used by many disciplines to inform understanding of how students progress their knowledge, skills and dispositional attributes to higher levels, leading to the ability to rationalise, make sound judgments and decisions, set priorities and generally think and act beyond the basic tenets of a defined discipline (Land, Meyer, \& Smith, 2008; Land, Meyer, \& Flanagan, 2016). There are three defining characteristics of threshold concepts. Firstly, a threshold concept is likely to be transformative, causing a significant shift in the way a person thinks about a particular learning event or experience, either in part or completely. Secondly, a threshold concept is probably irreversible; once a shift in thinking is acquired, new ways of thinking are unlikely to be forgotten. A third characteristic of a threshold concept is the integrative process of combining known with previously "hidden" or "new" knowledge, generating an altered perception of something. These characteristics are neither static nor simultaneous during a learning process. The transitional phase towards transformed or new understanding of a knowledge or practice context can be viewed as troublesome for learners, as they encounter uncertainty in this process (Perkins, 2006). They cannot return to what they previously knew, yet they may not be in a position to fully integrate previously unrelated knowledge into a new way of thinking or viewing something. Thus, it is important for educators to provide exposure to, experience of and scaffolding for students transitioning through amended or new portals of understanding.

The use of the threshold concepts framework to assist in the promotion of meaningful transformative learning and teaching experiences is considered by Neve (2019) as 
an important focus for research and practice. Indeed, threshold concepts have been described by Land, Neve and Martindale (2018) as being, specifically, discipline focused, which has allowed the framework to take hold in relation to knowledge acquisition and advancement in healthcare professions (Bhat, Burm, Mohan, Chahine, \& Goldszmidt, 2018; Kinchin, Cabot, Kobus, \& Woolford, 2011; Nicola-Richmond \& Pepin, 2016 Vaughan, 2016). However, the notion of threshold concepts does not currently provide either a discourse or a framework that has resonance across the collaborative practices of health professions. To our knowledge, the notion of threshold concepts has not previously been used to inform an interpretation of the temporal nature of learning experiences in an interprofessional healthcare practice environment.

This paper identifies threshold concepts (Meyer \& Land, 2003) following students' and educators' learning experiences during a practice-based program and provides insight into learning transitions towards an integrative, transformative understanding of interprofessional practice. The aim is to report on students' and educators' transformative learning to work collaboratively. It draws upon findings from a study exploring the experiences of students and clinical educators involved in a universitybased interprofessional health centre pilot program for patients living with Type 2 diabetes (O’Brien, McNaughton, Flood, Morgan, \& Bowmar, 2016).

\section{Study design}

\section{Context}

The interprofessional education program ran 1 day a week for 8 weeks and included student orientation sessions on interprofessional practice, diabetes and patient assessment tools, followed by 6 weeks of interprofessional interventions and education sessions for 12 patients with Type 2 diabetes. Each student was assigned as care coordinator to one patient, and all patient appointments were attended by student pairs from different disciplines. Collaborative student-led case conferences were held each week to review, discuss and plan subsequent interprofessional appointments. Patients were reassessed at the end of the program and a comprehensive report compiled and sent to their general medical practitioner and other relevant primary care practitioners.

\section{Methodology and methods}

The study utilised an exploratory mixed methodology, inclusive of quantitative and qualitative methods for data collection and analysis to authentically "legitimize multiple ways of seeing and hearing ... of making sense of the social world" (Greene, 2015, p. 750). Quantitative data was used to answer a different research question related to patient outcomes and is reported elsewhere (O'Brien et al., 2016). This paper reports on the in-depth qualitative methods for data collection and thematic analysis of the participants' learning experiences and interprets these through a threshold concepts framework. 


\section{Participants}

Fourteen final-semester health students (five males, nine females) from sport, exercise and nutrition (1), health promotion (2), nursing (2), occupational therapy (2), oral health (2), physiotherapy (2), podiatry (2) and counselling psychology (1) participated in the program and took part in one of two focus groups at the end. Students had experienced a variable amount of clinical placement, depending on their health discipline, prior to their participation in this program. Five clinical educators and two interprofessional facilitators (all female) had developed the pilot program collaboratively over several months and participated in the program. All but one of these educators and administrators took part in a third focus group.

\section{Data collection}

Ethics approval for the study was obtained from the Auckland University of Technology (AUT) Ethics Committee (AUTEC \#15/266). Informed written consent was given by all participants before the program and study commenced. Researchers conducted 60-minute focus groups with students (two groups of seven) and staff (one group of eight) after completion of the program. Focus group interviews were recorded digitally, and following transcription by an independent transcriber, transcripts were checked for accuracy by the research team. Participant's names were replaced with pseudonyms prior to data analysis to ensure anonymity of those who took part in the study.

\section{Data analysis}

Descriptive qualitative analysis of the data has been described elsewhere (O'Brien et al., 2016). Interpretive analysis followed an iterative process, progressing from independent reading of the transcripts by research team members to collaborative data-derived coding and construction of descriptive categories drawn directly from the focus group questions (Braun \& Clarke, 2013). Researchers searched the transcripts for recurrent shared and divergent meanings, which were discussed and refined collaboratively until agreement on the main themes and sub-themes was reached (Bryman, 2012; Denzin \& Lincoln, 2011). An outline was generated, linking the themes and sub-themes to the coded data, and participant text was selected to illustrate each, paying particular attention to retaining the meaning and context of participant quotes (Braun \& Clarke, 2006). During the analytic process, examples of transformative learning emerged, reported by participants as experiences that expanded their views and understanding of professions relating to one another. In particular, the integration of amended or new understanding of a holistic patient-centred approach to care from previous profession-centric practice became evident, reported in this paper as experiences of transformative learning using a threshold concepts framework. Specifically, through listening to the students' and educators' experiences and the meaning they attributed to interprofessional collaborative teamwork, examples of threshold concept learning characteristics were identified. 


\section{Results}

Engaging in an interprofessional program experience provided an opportunity for students and educators to transition from a predominantly profession-centric perspective on healthcare to a transformative practice shift of working in an interprofessional team. Language used by students and educators to describe their experiences indicated levels of uncertainty as they were grappling with new or altered knowledge and clinical practice. This was followed by a transitional state of either choosing to remain in an increasingly familiar professional field or, alternatively, choosing to navigate the unfamiliar territory found at the interface of professions, which comes with the associated blurring of knowledge and practice. Those who then progressed through a portal of new or altered perceptual awareness, resulting in "sense-making" of their clinical knowledge and practice when working interprofessionally, were able to explain instances when this transformation occurred for them.

The transformative learning thresholds experienced by students and educators were identified as:

- broadening perspectives on healthcare practice through integrating the "health priorities" of the patient and the other professions into individual health perspectives

- strengthening sense of professional self through engaging in professional role identification and clarification of distinct and common contributions to provision of care

- gaining an appreciation of holistic patient care through engaging in clinical practice experiences together with a number of professions about their patients

- actioning holistic, patient-centred healthcare through increasingly focusing on patient-centred care in real-time practice with their patients.

Each of the four transformational threshold concepts represents a shift in students' and educators' views and their sharing of knowledge and practices while engaging in interprofessional teamwork opportunities.

\section{Broadening perspectives on healthcare practice}

The experience of being involved in the interprofessional program, of undertaking collaborative patient assessments and appointments, provided integrative opportunities through expanding the lens by which students and educators viewed their practice context. Students described "broaden[ing] my mind, looking at things from other ways and also prioritising, because you found that the other professions had different priorities" (Natalie, nursing student) and collectively "looking at a person holistically [in the IP program]" (Rachel, podiatry student). Equally, educators observed transformative perspective changes as, "something had changed about the way [students] viewed health, the way that they viewed patients and the way they viewed those they worked with" (Alison, IP educator). On a personal level, one clinical educator's own understanding of interprofessional practice was transformed through the experience of working with students and patients in an explicitly collaborative structure, voiced as a comparison 
between multidisciplinary work, "where we get together in a meeting and everybody then gives bits and pieces" and interprofessional work, where "we actually plan and do the treatment together, manage the care together" (Diana, clinical educator).

\section{Strengthening sense of professional self}

The interprofessional real-time practice context was an opportunity for students and educators to experience new ways of working, both integrative and irreversible, through adapting and expanding their roles as part of a collaborative team. As the students were in the final stages of their undergraduate health degrees, they were themselves navigating a transitional role from student to practitioner. Staff commented that their facilitator role in guiding the students through this experience involved taking an increasingly hands-off approach, allowing students space to work through challenging or perplexing aspects of interprofessional collaborative practice. Initially, one educator grappled with being "supportive rather than actually almost overbearing ... there's that fine line between guiding, just keeping quiet and seeing what happens and then letting them fly" (Alison, interprofessional educator). Furthermore, one educator observed the effect of students' reciprocal communication on the contribution and role of each discipline in an interprofessional collaborative practice context and said:

Students were contributing from that [health stance] and they were all valued and respected for that ... They felt very proud of what they were contributing ... and then they were flourishing at the interface because they had to communicate that to each other. (Alison, interprofessional educator)

Students established and continually affirmed their identities as health practitioners with unique roles in the interprofessional team through the articulation of their distinct roles, where "each of us promotes our own profession" (Kate, occupational therapy student) and because "we had to talk about our profession, that meant we understood what our profession did and what other professions did, and it made it a lot easier to integrate" (Natalie, nursing student) and work together.

\section{Gaining an appreciation of holistic patient care}

Through reflection on the process of learning about other health disciplines, both educators and students often appeared astonished at the positive impact of working together in the program. One interprofessional educator summarised the transformative experience of integrating currently known with new knowledge and described "understanding more about podiatry, OT, physio, psychology than I'd ever done in the last 30 years of working in my own little silo" (Gillian, interprofessional educator). Similarly, one student spoke of the perceived benefit to his own practice of "really learning what they $d o$ " (Scott, sport and recreation student) from professions that he had not encountered until he participated in the program. This was expressed by another student as " $a$ big learning opportunity. I had a basic knowledge of what they do but not as in-depth as what I have now" (Melissa, oral health student). 
Active engagement in collaborative practice involved grappling with the multitude of health perspectives and aligning practice priorities that originate in distinct professions. This appears to have transitioned students through an integrative, irreversible conceptual threshold portal of understanding holistic, multifaceted and frequently complex patient concerns. One student expressed this as "knowing what other professions do and having other perspectives to pick up on what the patient is saying ... things that you wouldn't normally consider with the patient when I was just thinking about OT" (Laura, occupational therapy student).

Importantly, the program irreversibly altered both educators' and students' perspectives on what constituted patient-centred care, from focusing on the interaction between a single profession and patient(s) to integration of a holistic approach through collaboration among professions. Natalie (nursing student) described a transformation in her understanding of teamwork. "[Because] we had to talk about what our profession did, we found that we all had huge overlap". This helped her develop a greater understanding of her own nursing role, along with the roles of other professions, and as a result, she discovered that it 'made it a lot easier to integrate [various professions' knowledge and skills]" in the provision of patient care.

\section{Actioning holistic, patient-centred bealthcare}

The interprofessional practice context provided experiential learning opportunities for participants to transition from a position of profession-centricity towards patientcentred care, expressed by a nursing student as "working towards a common goal with the patient [and] there's a totally different feel ... to sit down with patients and say 'what are your goals', what are our goals and how can we join those goals together as a team" (Natalie, nursing student).

Another student compared a holistic approach to patient care with working in a single profession "where we don't see the overlap. ... It was really good to see how many minds [from a number of professions] think and how to become one" (Melissa, oral health therapy student). Positively expressing interprofessional experiences in this way signaled integrative and potentially irreversible transformative learning, both merits of collaborative practice. One student expressed working in this way as "a unity offocus in order to work together as a team" (Oliver, psychology student).

Educators also observed students learning through authentic interprofessional practice with each other and clients, with " $a$ number of patients saying on different occasions, anecdotally, that it's lovely being treated as a whole person. And a number of the students said its great working towards a number of things with people towards optimal health" (Alison, interprofessional educator).

This notion of patients being "treated as a whole person rather than just a part" (Kirsten, clinical educator) was an aim of the program, and Kirsten observed students' actioning holistic patient-centred practice with their patients, saying, "They could actually see the whole point of teamwork and what interprofessional practice actually meant". Scaffolding 
students' learning into transformed ways of viewing and responding in their relationship with clients was achieved, expressed by Kristen as, "The students got it".

\section{Discussion}

When applied to the current study findings, a threshold concepts framework provides a lens through which transformational portals of students' interprofessional learning, and grappling with new knowledge, skills and values (Meyer \& Land, 2006) through to altered healthcare perspectives can be identified. From having previously only considered a patient's presenting concerns from a specific disciplinary perspective, several students in the interprofessional program experienced a transformed view, or "broadened understanding", of patient needs through experiential learning that required the students to communicate and practise together (Reeves et al., 2013).

Transformative change, if and when it occurs, is frequently observed or spoken of as an "aha" or "wow" moment (Timmermans, 2010). When a learner progresses to new understanding, having progressed through a threshold portal as a result of a learning experience, he or she cannot return to the original state of knowing (Meyer \& Land, 2003). From this point forward, the learner has retained existing profession-related knowledge, skills and values, but also an additional layer or level of professional capacity for practising in an interprofessional manner (Davies, 2016; Morgan, 2017).

When the framework is applied to a clinical context, educators' and students' increased awareness and ongoing observation of what is said and done as they engage in collaborative learning among professions assists in the understanding of the threshold concepts framework as relevant to interprofessional practice. Furthermore, focusing on transformative learning "portals" when listening to students recount their interprofessional experiences during clinical practice informs educators and clinical practitioners on the learning processes in action (Argyris \& Schön, 1974). By reflecting on meaning as constructed in action by students, educators may become more attuned to structuring learning contexts to scaffold students towards and through threshold portals, developing a "pedagogy of threshold concepts" (Meyer \& Timmermans, 2016, p. 25). Furthermore, Neve (2019) stresses the important role for healthcare educators in "helping learners to cross troublesome but vital thresholds so that they are able to accept and embrace uncertainty" (p. 7), along with increasing the resilience required in complex clinical practice (Land et al., 2018)

Scaffolding is necessary, since the sheer volume and complexity of knowledge and skills to be acquired during interprofessional teamwork can leave a learner feeling uncertain at the edge of a threshold in familiar territory, and reluctant to step into the "unknown" of new learning experiences (Meyer \& Land, 2006). This may be prevented by reframing predominantly competency-based incremental learning outcomes to include specific, interprofessional, interactive processes (Thistlethwaite, 2015) that scaffold students learning from a basic to an integrated understanding of what it means to work collaboratively among health professions. In this regard, it is important to identify 
patient-centred threshold concepts that clearly require an interprofessional process in order to facilitate transformative learning.

This study has provided an exploratory lens into the transformative learning process. Although limited by the small number of participants, both educators and students, the research has identified the importance of evaluating an interactive process over time in order to identify key threshold concepts for interprofessional practice. Future research into identifying additional interprofessional practice threshold concepts, and building on those that have been identified, is important for developing this pedagogical field in healthcare practice.

\section{Conclusion}

The threshold concepts framework (Meyer \& Land, 2003) has provided a lens through which to view students' and educators' perspectives on the process of learning to practise interprofessionally, through attending to the learning processes and practitioner (student and educator) development occurring during a patient-centred, interprofessional education program. Specifically, by progressing through threshold portals, individuals showed progressive learning capability for complex multifaceted knowledge that may be counter-intuitive when compared with the distinct disciplinary knowledge of professional education programs.

Understanding threshold concepts can assist educators to identify transitional stages of student learning experiences, plus associated conceptual and practice thresholds at which students may need extra support or scaffolding to acquire new interprofessional perspectives and practices. This in turn will assist educators to construct interprofessional education and practice threshold concepts that are explicitly embedded in professional programs of study, with the aim of developing students' graduate capability for working interprofessionally in collaborative teams.

\section{Acknowledgements}

The research team wishes to acknowledge the study participants, the Auckland University of Technology Integrated Health clinic staff and School of Interprofessional Health Studies for their practical and financial support.

\section{Funding and conflicts of interest}

No funding or conflicts of interest are declared.

\section{References}

Argyris, C., \& Schön, D. A. (1974). Theory in practice: Increasing professional effectiveness. San Francisco, CA: Jossey-Bass.

Barr, H. (2013). Towards a theoretical framework for interprofessional education. Journal of Interprofessional Care, 27, 4-9. doi:10.3109/13561820.2012.698328 
Barr, H., Gray, R., Helme, M., Low, H., \& Reeves, S. (2016). Steering the development of interprofessional education. Journal of Interprofessional Care, 30(5), 549-552. doi:10.1080/13561820.2016.1217686

Bhat, C., Burm, S., Mohan, T., Chahine, S., \& Goldszmidt, M. (2018). What trainees grapple with: A study of threshold concepts on the medicine ward. Medical Education, 52, 620-631. doi:10.1111/medu.13526

Black, D. A., Taggart, J., Jayasinghe, U. W., Proudfoot, J., Crookes, P., Beilby, J., ... Harris, M. F. (2013). The teamwork study: Enhancing the role of non-GP staff in chronic disase management in general practice. Australian Journal of Primary Health, 19(3), 184-189. doi:10.1071/PY11071

Berger, S., Goetz, K., Leowardi-Bauer, C., Schultz, J., Szecsenyi, J., \& Mahler, C. (2017). Anchoring interprofessional education in undergraduate curricula: The Heidelberg story. Journal of Interprofessional Care, 31(2), 175-179. doi:10.1080/13 561820.2016 .1240156

Braun, V., \& Clarke, V. (2006). Using thematic analysis in psychology. Qualitative Research in Psychology, 3(2), 77-101. doi:10.1191/1478088706qp063oa

Braun, V., \& Clarke, V. (2013). Successful qualitative research: A practical guide for beginners. London, England: Sage.

Bryman, A. (2012). Social research methods. Oxford, England: Oxford University Press.

Cox, M., Cuff, P., Brandt, P., Reeves, S., \& Zierler, B. (2016). Measuring the impact of interprofessional education on collaborative practice and patient outcomes. Journal of Interprofessional Care, 30(1), 1-3. doi:10.3109/13561820.2015.1111052

Craddock, D., O’Halloran, C., McPherson, K., Hean, S., \& Hammick, M. (2013). A top-down approach impedes the use of theory? Interprofessional educational leaders' approaches to curriculum development and the use of learning theory. Journal of Interprofessional Care, 27(1), 65-72. doi:10.3109/13561820.2012 .736888

Davies, J. (2016). “Threshold Guardians": Threshold concepts as guardians of the discipline. In R. Land, J. H. F. Meyer, \& M. T. Flanagan (Eds.), Threshold concepts in practice (pp. 121-134). Rotterdam, The Netherlands: Sense.

Denzin, N., \& Lincoln, Y. (2011). The sage handbook of qualitative research. California, CA: Sage.

Farlow, J. L., Goodwin, C., \& Sevilla, J. (2015). Interprofessional education through service-learning: Lessons from a student-led free clinic. Journal of Interprofessional Care, 29(3), 263-264. doi:10.3109/13561820.2014.936372

Frenk, J., Chen, L., Bhutta, Z., Cohen, J., Crisp, N., Evans, T., . . Zurayk, H. (2010). Health professionals for a new century: Transforming education to strengthen health systems in an interdependent world. The Lancet Commissions, 376(9757), 1923-1958. doi:10.1590/S1726-46342011000200023 
Grant, A., Mackenzie, L., \& Clemson, L. (2015). How do general practitioners engage with allied health practitioners to prevent falls in older people? An exploratory qualitative study. Australasian Journal on Aging, 34(3), 149-154. doi:10.1111/ajag.12157

Green, C. (2013). Relative distancing: A grounded theory of how learners negotiate the interprofessional. Journal of Interprofessional Care, 27(1), 34-42. doi:10.3109/ 13561820.2012.720313

Greene, J. C. (2015). The emergence of mixing methods in the field of evaluation. Qualitative Health Research, 25(6), 746-750. doi:10.1177/104973231556499

Hean, S., Anderson, E., Bainbridge, L., Clark, P. G., Craddock, D., Doucet, S., ... Oandasan, I. (2013). IN-2-THEORY-Interprofessional theory, scholarship and collaboration: A community of practice. Journal of Interprofessional Care, 27(1), 88-90. doi:10.3109/13561820.2012.743979

Hean, S., Anderson, E., Green, C., Pitt, J. R., \& O’Halloran, C. (2016). Reviews of theoretical frameworks: Challenges and judging the quality of theory application. Medical Teacher, 38(6), 613-620. doi:10.3109/014259X.2015.1075648

Kinchin, M., Cabot, L. B., Kobus, M., \& Woolford, M. (2011). Threshold concepts in dental education. European Journal of Dental Education, 15(4), 210-215. doi:10.1111/j.1600-0579.2010.00660.x

Land, R., Meyer, J. H. F., \& Smith, J. (Eds.). (2008). Threshold concepts within the disciplines. Rotterdam, The Netherlands: Sense.

Land, R., Meyer, J. H. F., \& Flanagan, M. T. (Eds.). (2016). Threshold concepts in practice. Rotterdam, The Netherlands: Sense.

Land, R., Neve, H., \& Martindale, L. (2018). Threshold concepts, action poetry and the health professions: An interview with Ray Land. International Journal of Practice-based Learning in Health and Social Care, 6(1), 45-52. doi:10.18552/ ijpblhsc.v6i1

Lie, D. A., Forest, C. P., Walsh, A., Banzali, Y., \& Lohenry, K. (2016). What and how do students learn in an interprofessional student-run clinic? An educational framework for team-based care. Medical Education Online, 21(31900), 1-10. doi: $10.3402 /$ meo.v21.31900

Meyer, J. H. F., \& Land, R. (2003). Threshold concepts and troublesome knowledge: Linkages to ways of thinking and practising within the disciplines. In C. Rust (Ed.), Improving student learning: 10 years on (pp. 412-424). Oxford, England: OCSLD.

Meyer, J. H. F., \& Land, R. (2006). Threshold concepts and troublesome knowledge: Issues of liminality. In J. H. F. Meyer \& R. Land (Eds.), Overcoming barriers to student learning: Threshold concepts and troublesome knowledge (pp. 19-33). London, England: Routledge.

Meyer, J. H. F., \& Timmermans, J. A. (2016). Integrated threshold concept knowledge. In R. Land, J. H. F. Meyer, \& M. T. Flanagan (Eds.), Threshold concepts in practice (pp. 25-28). Rotterdam, The Netherlands: Sense. 
Morgan, C. J. (2017). Graduates' development of interprofessional practice capability during their early socialisation into professional roles. Journal of Interprofessional Care, 31(4), 438-445. doi:10.1080/13561820.2017.1295029

Neve, H. (2019). Learning to become a primary care professional: Insights from threshold concept theory. Education for Primary Care, 30(1), 5-8. doi:10.1080/14 739879.2018.1533390

Nicola-Richmond, K. M., \& Pepin, G. (2016). Transformation from student to occupational therapist: Using the Delphi technique to identify the threshold concepts of occupational therapy. Australian Occupational Therapy, 63, 95-104. doi:10.1111/1440-1630.12252

O’Brien, D., McNaughton, S. M., Flood, B., Morgan, C. J., \& Bowmar, A. (2016). Piloting an integrated, interprofessional programme for people living with Type II diabetes: Outcomes and experiences. Australian Journal of Clinical Education, 1(1), $1-16$.

Olson, R., \& Bialocerkowski, A. (2014). Interprofessional education in allied health: A systematic review. Medical Education, e48(3), 236-246. doi:10.1111/ medu. 12290

Perkins, D. (2006). Constructivism and troublesome knowledge. In J. H. F. Meyer $\&$ R. Land. (Eds.), Overcoming barriers to student understanding: Threshold concepts and troublesome knowledge (pp. 33-48). London, England: Routledge.

Reeves, S. (2016). Ideas for the development of the interprofessional education and practice field: An update. Journal of Interprofessional Care, 30(4), 405-407. doi:10. 1080/13561820.2016.1197735

Reeves, S., \& Hean, S. (2013). Why we need theory to help us better understand the nature of interprofessional education, practice and care. Journal of Interprofessional Care, 27(1), 1-3. doi:10.3109/13561820.2013.751293

Reeves, S., Perrier, L., Goldman, J., Freeth, D., \& Zwarenstein, M. (2013). Interprofessional education: Effects on professional practice and healthcare outcomes (update). Cochrane Database of Systemic Reviews, 2013(3). doi:10.1002/14651858.CD002213.pub3

Reeves, S., Boet, S., Zierler, B., \& Kitto, S. (2015). Interprofessional education and practice guide No. 3: Evaluating interprofessional education. Journal of Interprofessional Care, 29(4), 305-312. doi:10.3109/13561820.2014.1003637

Thistlethwaite, J. E. (2012). Interprofessional education: A review of context, learning and the research agenda. Medical Education, 46(1), 58-70. doi:10.1111/j.13652923.2011.04143.x

Thistlethwaite, J. E. (2015). Interprofessional education and the basic sciences: Rationale and outcomes. Anatomical Sciences Education, 8, 299-304. doi:10.1002/ ase. 1521 
Timmermans, J. A. (2010). Changing our minds: The developmental potential of threshold concepts. In J. H. F. Meyer, R. Land., \& C. Baillie (Eds.), Threshold concepts and transformational learning (pp. 3-19). Rotterdam, The Netherlands: Sense.

Vaughan, K. (2016). Vocational thresholds: Developing expertise without certainty in general practice medicine. Journal of Primary Care, 8(2), 99-105. doi:10.1071/ HCI15027

Watkins, K. D. (2016). Faculty development to support interprofessional education in healthcare professions: A realist synthesis. Journal of Interprofessional Care, 30(6), 695-701. doi:1080/13561820.2016.1209466

Weller, J., Thwaites, J., Bhoopatkar, H., \& Hazell, W. (2010). Are doctors team players, and do they need to be? The New Zealand Medical Journal, 123(1310), 109-117.

World Health Organization (WHO). (2010). Framework for action on interprofessional education and collaborative practice. Retrieved from http://whqlibdoc.who.int/ hq/2010/WHO_HRH_HPN_10.3_eng.pdf

World Health Organization (WHO). (2013). Transforming and scaling up health professionals' education and training. Retrieved from http://www.who.int/hrh/ resources/transf_scaling_hpet/en

World Health Organization (WHO). (2016, April). Framework on integrated, peoplecentred health services: Report by the Secretariat (Report No. A69/39). Retrieved from https://apps.who.int/gb/ebwha/pdf_files/WHA69/A69_39-en.pdf

Zepke, N. (2013). Threshold concepts and student engagement: Revisiting pedagogical content knowledge. Active Learning in Higher Education, 14(2), 97-107. doi:10.1177/1469787413481127 